\title{
Comparing the potentials of clay and biochar in improving water retention and mechanical resilience of sandy soil
}

\author{
Ayodele Ebenezer Ajayi ${ }^{1,2 *}$ and Rainer Horn ${ }^{2}$ \\ ${ }^{1}$ Department of Agricultural and Environmental Engineering, Federal University of Technology, \\ PMB 704, Akure, Ondo State, Nigeria \\ ${ }^{2}$ Institute for Plant Nutrition and Soil Science, CAU Kiel, Hermann Rodewald str. 2, 24118 Kiel, Germany
}

Received February 15, 2016; accepted August 2, 2016

\begin{abstract}
A b s t r a c t. Changing climate is threatening rainfall regularity particularly in the semi-arid and arid regions; therefore, strategies to conserve water within their coarse-grained soils and to improve water use efficiency of crops are critical. This study compared the effectiveness of biochar and two types of clay materials in augmenting water retention and improving mechanical resilience of fine sand. The amendment of fine sand with woodchip-biochar and kaolinite (non-swelling clay) and Na-bentonite (swelling clay) improved the water retention capacity and interparticle bonding of the substrate depending of the rate of amendment and water content of the substrates. Na-bentonite was more effective at increasing water retention capacity at more negative matric potentials. Biochar was more effective at saturation due to the increased porosity, while kaolinite responds similarly to biochar. It is, however, shown that most of the water retained by the Na-betonite may not be available to plants, particularly at high amendment rate. Furthermore, the clay and biochar materials improved particle bonding in the fine sand with the Na-bentonite being more effective than biochar and kaolinite (in that order) in strengthening interparticle bonds and improving the resilience of fine sand, if the rate of amendment is kept at $\leq 50 \mathrm{~g} \mathrm{~kg}^{-1}$.

$\mathrm{K}$ e y w o r d s: rheometry, biochar, clay minerals, water retention, interparticle strength, sandy soil
\end{abstract}

\section{INTRODUCTION}

The availability of water in the soil to plants in the right quantity and at the right time is critical for optimal crop production in both rainfed and irrigated agriculture. Moreover, the storage and release of the available water by the soil during the growing season should be optimized according to the plant demand. However, scenarios of climatic changes are threatening rainfall supplies and

\footnotetext{
*Corresponding author e-mail: ayo.ajayi@gmail.com
aeajayi@futa.edu.ng

*Corresponding author e-mail: ayo.ajayi@gmail.com
aeajayi@futa.edu.ng
}

regularity particularly in the semi-arid and arid regions (Cai et al., 2014). Therefore, several strategies to conserve water within the soil and to improve water use efficiency of crops are evolving. For instance, the implementation of conservation tillage in different parts of southern Europe aimed mainly at improving retention of water in the soil and reducing erosion (Bescansa et al., 2006). Similarly, the practice of reduced tillage along with stubble retention by farmers in southern Australia is a method of improving water retention and reducing erosion in their prevailing sandy soils (Roper et al., 2013). It is believed that combining these practices would increase the levels of soil carbon (principally derived from the retained crop residues), and to improve water retention properties of the soil. Besides, water-retention additives like hydrophilic polymers (hydrogel) and silicate granules have been applied to soils to increase water holding capacity (WHC) and to improve plant available water (PAW) in substrates (Farrell et al., 2013; Shahid et al., 2012). Hydrophilic polymers are super absorbents that absorb and store water up to 500 times their own weight when saturated (Johnson, 1984), whereas the silicate-based granules contain natural silicate based stone powders $\left(\mathrm{SiO}_{2}\right)$, carbon compounds and cellulose that attach to the surface of soil particles and thereby increase the available surface area for nutrient and water sorption (Sanoway Australia, 2006).

Furthermore, the amendment of sandy soils with clay ('claying') is a traditional practice in many arid and semiarid areas of the world, and has been shown to have very useful economic and ecological benefits in crop production 
(Dempster et al., 2012). The added clay, buffered for the amended soil $\mathrm{pH}$, improves cohesion of the soil particles and enhances hydrophilicity. Concurrently, the clay particle supplies some micro nutrients and improves nutrient retention capacity of the substrate (Karbout et al., 2015; Meisl et al., 2013; Ward and Oades, 1993). Moreover, clays have been found to be very effective at reducing water repellency in water repellent sands (McKissock et al., 2000). In recent times, the use of biochar, in performing similar roles of improving water and nutrient retention capacity in the soil, while sequestering carbon, has received considerable attention (Ajayi et al., 2016; Dempster et al., 2012; Obia et al., 2016). Biochar is therefore widely promoted as an alternative soil amendment, particularly for coarse textured and poorly structured soils (Abel et al., 2013; Bruun et al., 2014; Mulcahy et al., 2013; Obia et al., 2016) and for mitigation of climate change related drought stress in agriculture (Liang et al., 2014).

In general, the basic principle behind the effectiveness of any soil amendment material or additive apart from nutrient enhancement (in some cases) is the ability of such material or additive to effect some positive microstructural changes in the soil (Ajayi et al., 2016; Donn et al., 2014; Yoo et al., 2014). For instance, the increase in surface area and the attendant enhancement of available binding sites, the improved aggregation and concomitant decrease in tensile strength and changes in pore configuration (modification of the proportions of wide-coarse, narrow-coarse, medium and fine pores) in amended soils are direct consequences of microstructural changes in the amended soil (Ajayi et al., 2016; Arthur et al., 2014; Yoo et al., 2014). However, this particle to particle scale changes have not been well elaborated in several studies that aimed to analyse the consequence of soil amendments. Equally, there is no study that we know, that has compared microstructural changes in soil amended with biochar and clay material.

Rheological methods have been useful in investigating microstructural changes in substrates. Rheological measurements and parameters derived thereof, have adequately characterized micro-mechanical behaviour in substrates and elucidate differences in resilience criteria at particle-to-particle scale (Holthusen et al., 2012; Markgraf et al., 2012). The amplitude sweep test (AST) in particular has been used to evaluate the impact of some soil amendment materials, including fertilizers and biochar on the properties of the resulting substrate (Ajayi et al., 2016; Holthusen et al., 2012; Markgraf and Horn, 2006; Markgraf et al., 2012). Rheological parameters like storage and loss moduli, loss factor $\tan (\partial)$ and integral $\mathrm{z}$ describe the internal strength and maximum interparticle shear stress in substrates (The basic theory as well as a summarizing theory documentation on rheological techniques in soil research could be found in Holthusen et al., 2012; Markgraf et al., 2006; 2012; Vyalov, 2013).
Therefore, our objective in this paper was to investigate the changes in mechanical strength and water retention as physical properties that define structure formation and stability in a fine-sand material amended with:

- biochar,

- kaolinite - a non-swelling clay and

- Na-bentonite - a swelling clay, at 3 different rates using rheometry techniques.

\section{MATERIALS AND METHODS}

A pre-graded fine sand, $F S(0.13-0.36 \mathrm{~mm})$ that consists of $100 \%$ quartz with negligible cation exchange capacity was separately amended with 3 materials:

- biochar $(B)$,

- kaolinite $(C 1)$ and

- Na-bentonites, Ibeco Seal-80 - (IS-80) (C2).

The biochar was prepared through slow pyrolysis of woodchips and forest residue by a commercial producer (Susterra - nachhaltig pflanzen; www.susterra.de). The pyrolytic carbonization occured at temperature range of $500-600^{\circ} \mathrm{C}$.

The kaolinite (a non-expandable) clay mineral (sand $5.4 \%$, silt $-19.2 \%$; clay $-75.4 \%$ ) is a clayey oxisol (WRB: Ferralsol) sampled from Santo Angelo Rio Grande do Sul, Brazil.

The Na-bentonites, Ibeco Seal-80 (IS-80; sand - 1.9\%, silt $-29.8 \%$; clay $-71.6 \%$ ), is an activated bentonite ie bentonite with smectites whose initial composition of alkaline earth cations has been replaced with $\mathrm{Na}^{+}$, in a technical process named alkali activation (Markgraf et al., 2006). It has a very high swelling potential.

For each amendment material, 3 sets of substrates were prepared by adding 20,50 or $100 \mathrm{~g}$ of the amendment material in every kilogram of prepared substrate. Each substrate type was manually mixed, sieved $(\leq 2 \mathrm{~mm})$, slightly moistened, and packed in sealed polythene bags at $10^{\circ} \mathrm{C}$, before they were used to prepare the test samples. Consequently, we have nine substrates: $F S 2 B, F S 5 B, F S 10 B, F S 2 C 1, F S 5 C 1$, $F S 10 C 1, F S 2 C 2, F S 5 C 2, F S 10 C 2$, with the numbers 2, 5 and 10 , indicating the proportion of added amendment material (biochar $-B$, clay $1-C 1$ or clay $2-C 2$ ). For each substrate, 20 replicated test samples were prepared by repacking $100 \mathrm{~cm}^{3}$ (4 cm height, $5.65 \mathrm{~cm}$ diameter) stainless steel cylinders with the substrates manually. A set of samples was similarly prepared with unamended fine-sand material and labelled $F S$. All the samples were prepared to a uniform bulk density of $1.65 \mathrm{~g} \mathrm{~cm}^{-3}$ and saturated by capillary rise for about $48 \mathrm{~h}$, except for substrates of the swelling clay (at 50 and $100 \mathrm{~g} \mathrm{~kg}^{-1}$ rates) that required more days to be saturated. Therefore the experimental set up consisted of 3 sets of amendment material x 3 rates of amendment and 1 set of an unamended control. 
The saturated samples were drained stepwise to matric potentials of $-6,-15,-30,-50 \mathrm{kPa}$ on ceramic plates. At each drainage step, the samples were weighed. Eventually, the dry bulk density was determined after drying the cores in the oven at $105^{\circ} \mathrm{C}$ for $16 \mathrm{~h}$. Total porosity (TP), air capacity (AC) and available water capacity (AWC) were calculated according to Hartge and Horn (2016), assuming a particle density of $2.65 \mathrm{~g} \mathrm{~cm}^{-3}$. The gravimetric water content at permanent wilting point $(-1500 \mathrm{kPa})$ for the samples was determined with homogenized (grinded and sieved $<2 \mathrm{~mm}$ ) samples, which were thoroughly moistened and packed in very small rings (20 samples per treatment). They were pneumatically drained on ceramic plates, placed within a pressure chamber for about 21 days and later oven dried at $105^{\circ} \mathrm{C}$ for $16 \mathrm{~h}$.

Rheological measurements were carried-out to detect differences in the stability parameters of the unamended fine sand and amended substrates, in relation to the type of amendment material, the rate of amendment and the matric potential. The rheological test samples were prepared with sieved samples $(\leq 2 \mathrm{~mm})$, repacked in $35 \mathrm{~cm}^{3}$ rings ( $3 \mathrm{~cm}$ height, $3.85 \mathrm{~cm}$ diameter). For the pre-treatment, the samples were first saturated by capillary rise and drained to $-6 \mathrm{kPa}$ on a sand bath. The samples were then neatly wrapped and stored at this state for about 140 days in a controlled environment (about $10^{\circ} \mathrm{C}$ ). The pre-treatment was to allow proper mixing and aggregation in the substrates. For the rheological test, the samples were re-saturated by capillary rise, and equilibrated to $0,-6$ and $-15 \mathrm{kPa}$ for each treatment. The test samples for the AST were prepared according to Ajayi et al. (2016). The AST with a controlled shear deformation (CSD) were carried out with a MCR 300 rheometer (Anton Paar, Stuttgart, Germany) with a $25 \mathrm{~mm}$ diameter parallel-plate measuring system. The AST settings followed the recommendation of Markgraf et al. (2006, 2012), in which the deformation in the sample when subjected to an oscillatory shear force for $15 \mathrm{~min}$ at a constant frequency of $0.5 \mathrm{~Hz}$, is noted every $30 \mathrm{~s}$. Interparticle forces and the corresponding microscale strength of the samples, within the linear viscoelastic (LVE) range, were determined from the storage and loss moduli (stored and lost deformation energy during the AST). The 'storage' modulus $\left(\mathrm{G}^{\prime}\right)$ (sometimes called dynamic rigidity) represents the stress energy that is temporarily stored in the particles during the AST, and can be recovered afterwards. On the other hand, the loss modulus $\left(\mathrm{G}^{\prime \prime}\right)$ indicates the energy which has been used to initiate flow (transformed into shear heat) during the AST, and is irreversibly lost (Schramm, 1994; Vyalov, 2013). Moreover, the microstructural behaviour of the substrates was evaluated from the dimensionless loss factor $\tan (\partial)$. The loss factor, $\tan (\partial)$, is the ratio of the loss modulus $\mathrm{G}^{\prime \prime}$ (Pa) (= viscous constituents) to the storage modulus $\mathrm{G}^{\prime}$ (Pa) (= elastic constituents) for a sample during the AST. A quantitative parameter, integral $\mathrm{z}$, was calculated from the characteristic AST curve for each sample. Integral z provides a semi-quantitative index of the stiffness degradation or mechanical resilience of the substrate, to the shearing force (for more details see Ajayi and Horn, 2016; Markgraf et al., 2012). The shear stress experienced by the sample during the AST indicates the shear resistance of the tested samples and relates well to shear strength parameters obtained from macro scale measurement in shear box and oedometer (Holthusen et al., 2012; Markgraf et al., 2012).

Statistical assessments of possible differences in the responses of the substrates during the various tests, were first investigated in a one-way analysis of variance of the raw data, followed by post hoc testing in pairwise multiple comparisons with the unamended control group (Holm-Sidak method). The overall significance level for Holm-Sidak tests was $p=0.05$. In instances where the data fails the 'Shapiro-Wilk' normality test, we run the nonparametric Kruskal-Wallis one-way analysis of variance on ranks in the first instance, and then used the Dunnet method to compare each treatment with the control. All statistical analyses were performed with SigmaPlot software v 12 (Systat Software, Point Richmond, CA, USA).

\section{RESULTS}

The volumetric water content (mean and standard deviation) of the substrates and the unamended fine-sand at different matric potentials is presented in Table 1. Water retention of the fine sand was improved by amendment with biochar, kaolinite and Na-bentonite (IS-80), even at the lowest amendment rate. However, the level of significance varied with the type of amendment material and the rate of amendment (Table 1). Generally, amending the fine sand material with $20 \mathrm{~g} \mathrm{~kg}^{-1}$ of any of the 3 materials did not significantly increase the total porosity. However, total porosity (volumetric water content at $0 \mathrm{kPa}$ ) was significantly increased $(p<0.05)$, when the amendment rate was increased to 50 and $100 \mathrm{~g} \mathrm{~kg}^{-1}$. As the samples were drained to $-6 \mathrm{kPa}$, the swelling clay increased the retained water significantly $(\mathrm{p}<0.001)$. The most significant impact on retained water could be detected for Na-bentonites (IS-80) (Table 1).

The changes in pores size distribution depends on the amendment material and its magnitude in the substrates. Amending the fine sand with either biochar or kaolinite had no significant effect on the narrow coarse pores $(0.5-50 \mu \mathrm{m})$ at the 3 rates considered. Moreover, they did not significantly decrease the wide coarse pore fraction $(>50 \mu \mathrm{m})$ or increased the medium $(<10-0.5 \mu \mathrm{m})$ and fine pores $(<0.2 \mu \mathrm{m})$, until their magnitude, in the amended fine sand reached 50 and $100 \mathrm{~g} \mathrm{~kg}^{-1}$ (Fig. 1a, b).

Amending the fine sand with Na-bentonites (IS-80), significantly decreased $(p<0.001)$ the wide and narrow coarse pores (Fig. 1c), even at the lowest rate of amendment $\left(20 \mathrm{~g} \mathrm{~kg}^{-1}\right)$. Simultaneously the medium and fine pores 
T a b l e 1. Volume of water retained (\%) as a function of the types and rates of amendments compared with the unamended fine sand at the various matric potentials $(\mathrm{kPa})$. FS0 - Fine sand with no amendment(control), FS2B - Fine sand $+20 \mathrm{~g} \mathrm{~kg}^{-1} \mathrm{Biochar}$ FS5B -

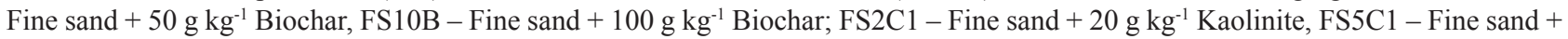
$50 \mathrm{~g} \mathrm{~g} \mathrm{~kg}^{-1}$ Kaolinite, FS10C1 - Fine sand $+100 \mathrm{~g} \mathrm{~kg}^{-1}$ Kaolinite; FS2C2 - Fine sand $+20 \mathrm{~g} \mathrm{~kg}^{-1} \mathrm{Na}^{-B e n t o n i t e, ~ F S 5 C 2 ~-~ F i n e ~ s a n d ~+~}$ $50 \mathrm{~g} \mathrm{~kg}^{-1} \mathrm{Na}$-Bentonite, FS10C2 - Fine sand $+100 \mathrm{~g} \mathrm{~kg}^{-1} \mathrm{Na}$-Bentonite. a - significant at $\mathrm{p}<0.05, \mathrm{~b}-$ significant at $\mathrm{p}<0.001$, and $\mathrm{n}-\mathrm{not}$ significant changes compared with the control. Average of 20 samples per treatment

\begin{tabular}{ccccccccccc}
\hline $\mathrm{kPa}$ & FS0 & FS2B & FS2C1 & FS2C2 & FS5B & FS5C1 & FS5C2 & FS10B & FS10C1 & FS10C2 \\
\hline 0 & $38.6 \pm 0.2$ & $42.5 \pm 0.8 \mathrm{~N}$ & $41.2 \pm 0.9 \mathrm{n}$ & $41.2 \pm 1.2 \mathrm{n}$ & $43.7 \pm 0.8 \mathrm{a}$ & $41.7 \pm 0.4 \mathrm{a}$ & $42.6 \pm 0.9 \mathrm{a}$ & $48.8 \pm 3.0 \mathrm{a}$ & $42.4 \pm 0.4 \mathrm{a}$ & $46.5 \pm 0.6 \mathrm{a}$ \\
-6 & $16.9 \pm 2.2$ & $19.6 \pm 1.2 \mathrm{a}$ & $19.8 \pm 0.9 \mathrm{a}$ & $28.5 \pm 0.8 \mathrm{~b}$ & $21.5 \pm 0.5 \mathrm{a}$ & $22.6 \pm 0.4 \mathrm{~b}$ & $33.6 \pm 0.7 \mathrm{~b}$ & $27.8 \pm 2.2 \mathrm{a}$ & $27.9 \pm 0.6 \mathrm{~b}$ & $37.2 \pm 0.7 \mathrm{~b}$ \\
-15 & $4.4 \pm 1.1$ & $7.3 \pm 0.8 \mathrm{n}$ & $5.9 \pm 0.5 \mathrm{n}$ & $20.9 \pm 0.8 \mathrm{~b}$ & $10.0 \pm 0.4 \mathrm{a}$ & $9.4 \pm 0.4 \mathrm{a}$ & $31.8 \pm 1.1 \mathrm{~b}$ & $17.1 \pm 2.5 \mathrm{a}$ & $15.6 \pm 0.5 \mathrm{a}$ & $34.8 \pm 1.6 \mathrm{~b}$ \\
-30 & $3.2 \pm 0.6$ & $4.2 \pm 1.1 \mathrm{a}$ & $4.3 \pm 0.7 \mathrm{n}$ & $17.8 \pm 1.5 \mathrm{~b}$ & $6.3 \pm 0.4 \mathrm{~b}$ & $7.6 \pm 0.6 \mathrm{a}$ & $27.2 \pm 0.7 \mathrm{~b}$ & $9.7 \pm 2.2 \mathrm{~b}$ & $13.2 \pm 2.1 \mathrm{a}$ & $32.3 \pm 1.6 \mathrm{~b}$ \\
-50 & $1.8 \pm 0.3$ & $2.7 \pm 1.4 \mathrm{n}$ & $2.1 \pm 0.7 \mathrm{n}$ & $15.6 \pm 2.1 \mathrm{n}$ & $4.5 \pm 1.1 \mathrm{a}$ & $5.1 \pm 0.6 \mathrm{a}$ & $25.2 \pm 0.8 \mathrm{a}$ & $7.3 \pm 1.8 \mathrm{a}$ & $11.7 \pm 2.2 \mathrm{a}$ & $31.0 \pm 1.3 \mathrm{a}$ \\
-1500 & $0.8 \pm 0.2$ & $1.0 \pm 0.1 \mathrm{n}$ & $1.8 \pm 0.3 \mathrm{a}$ & $8.3 \pm 0.9 \mathrm{~b}$ & $1.8 \pm 0.2 \mathrm{a}$ & $2.3 \pm 0.4 \mathrm{a}$ & $9.6 \pm 0.9 \mathrm{~b}$ & $3.0 \pm 0.1 \mathrm{a}$ & $3.7 \pm 0.6 \mathrm{a}$ & $12.4 \pm 2.3 \mathrm{~b}$ \\
\hline
\end{tabular}

were significantly $(p<0.05)$ increased, with greater magnitude of increase in these pore fractions compared with the other 2 amendment materials considered in the study.

Generally, shear stress and storage modulus were greater in the drained sample $(-6 \mathrm{kPa})$ than in the saturated samples $(0 \mathrm{kPa})$. The shear behaviour of the fine sand was modified when it was amended particularly by the Na-bentonites. The changes depend on the type of amendment material, the rate of amendment and the matric potential (Fig. 2 and b). At saturation $(0 \mathrm{kPa})$, the addition of $20 \mathrm{~g} \mathrm{~kg}^{-1}$ of biochar, kaolinite or Na-bentonites (IS-80) barely changed the shear stress if compared with the unamended soil (Fig. 2). The interparticle friction was mostly affected by the free water. With increase in amendment rates, the shear stress was significantly $(\mathrm{p}<0.05)$ increased even at the saturated state, except in the sample amended with kaolinite, whose particle size was very similar to the fine sand and did not swell at saturation.

When the samples were drained to $-6 \mathrm{kPa}$, the interparticle shear stress (maximum shear stress) increased in the amended substrates compared with the unamended soil, except for the $20 \mathrm{~g} \mathrm{~kg}^{-1}$ of biochar amendment which showed the opposite behaviour. The increases were much higher in the samples amended with Na-bentonites due to the predominantly sliding shear behaviour during the test (Fig. 2b). The storage modulus (dynamic rigidity), which is indicative of the mechanical resilience of the particles, was significantly increased $(\mathrm{p}<0.05)$ with the $50 \mathrm{~g} \mathrm{~kg}^{-1}$ of biochar and Na-bentonite when the samples were saturated but decreased again when the rate of amendment was increased to $100 \mathrm{~g} \mathrm{~kg}^{-1}$. For the samples drained to $-6 \mathrm{kPa}$, storage moduli were statistically similar, although the peak values differed.

The AST characteristics curve differed depending on the rate of amendment. The yield point ie the state of transition from an elastic behaviour to viscous behaviour of the substrate, was more accentuated as the amount of added materials increased. At saturation $(0 \mathrm{kPa})$, an amendent rate of $20 \mathrm{~g} \mathrm{~kg}^{-1}$ resulted in a comparable behaviour of the unamended fine sand and the 3 amended materials (Fig. 3a-c). This is further proven by the integral $\mathrm{z}$ values which were 24, 24.1 and 22.4 for the biochar, kaolinite and IS-80 amended fine sand at this matric potential, respectively (Table 2). When the amendment rate was increased to $50 \mathrm{~g} \mathrm{~kg}^{-1}$, the interparticle resistance that must be exceeded to reach a viscous state was increased in the biochar and Na-bentonites amended fine sand with the integral $\mathrm{z}$ value of 26.2 and 37.4. However, the interparticle resistance of the fine sand amended with kaolinite decreased. An amendment rate of $100 \mathrm{~g} \mathrm{~kg}^{-1}$ for both clay materials resulted in a microstructural collapse of the substrate with integral $\mathrm{z}$ values of 12.1 and 6.2 for the kaolinite and Na-bentonite while biochar amended fine sand had an Integral $\mathrm{z}$ value of 30.7 (Table 2).

At $-6 \mathrm{kPa}$ matric potential were the samples generally more rigid, with greater integral $\mathrm{z}$ values (Fig. 3d-f, Table 2). The attainment of the yield points was delayed by the different amendment materials when compared to the| unamended fine sand, except in the soil amended with $20 \mathrm{~g} \mathrm{~kg}^{-1} \mathrm{kaolinite}$. When the samples were further drained to a more negative matric potential $(-15 \mathrm{kPa})$, integral z generally decreased, highlighting the dominating importance of the menisci forces and the corresponding saturation degree of the samples over the effect of the different amendment materials (Table 2).

\section{DISCUSSION}

It is well known that the addition of finer particles with higher particle surface density to coarser material results in an increase in finer pores as well as an increased water storage capacity (Hartge and Horn, 2016). These effects could be confirmed with our data, which showed that the three amendment materials (biochar, kaolinite, Na-bentonite) can be used to furthermore increase the water holding 
a

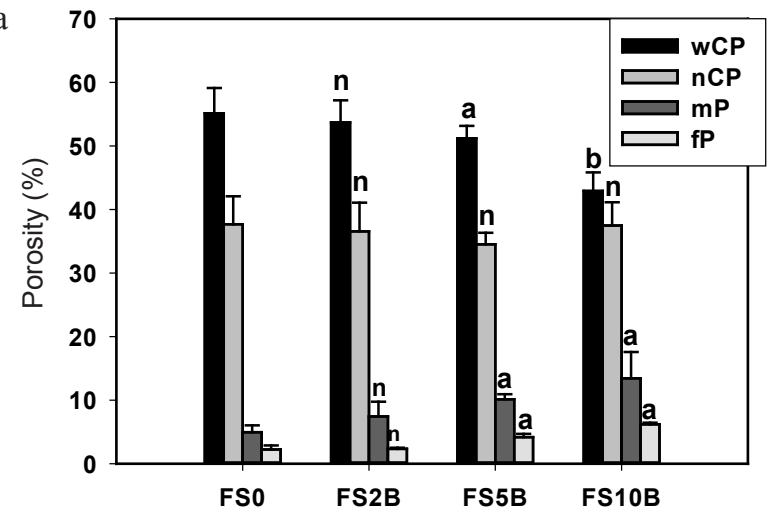

b
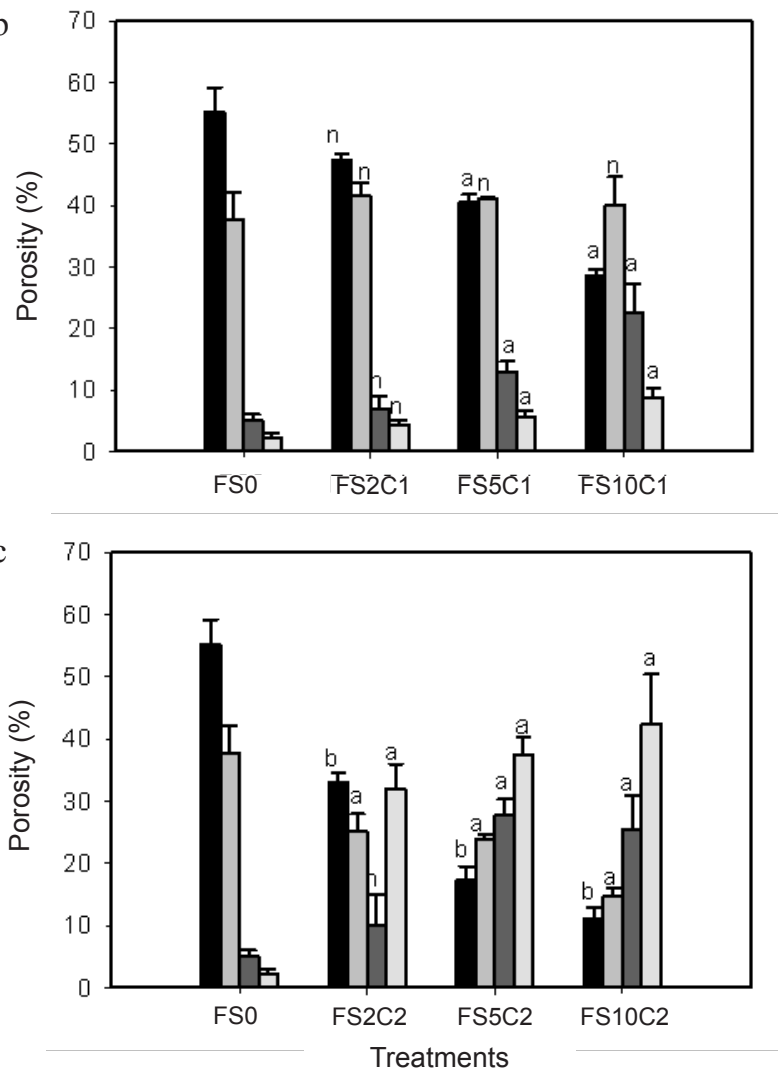

Fig. 1. Changes in pore size distribution in the fine sand due to amendment with: a) biochar, b) kaolinite, and c) Na-bentonites (IS-80). Letter $\mathrm{a}-\mathrm{p}<0.05, \mathrm{~b}-\mathrm{p}<0.001$ and $\mathrm{n}-$ not significant when the effect of amendment is compared in one - ANOVA with the unamended fine sand. wCP - wide coarse pore fraction $(>50 \mu \mathrm{m}) ; \mathrm{nCP}$ - narrow coarse pore fraction $(0.5-50 \mu \mathrm{m})$; $\mathrm{mP}-$ medium pore fraction $(<10-0.5 \mu \mathrm{m})$ and $\mathrm{fP}-$ fine pore fraction $(<0.2 \mu \mathrm{m})$.

capacity of fine sand, although the level of effectiveness differed, depending on the rates of amendment and the matric potential considered. This capability of the materials will be very helpful to enhance agricultural productivity in these soils, which often undergo extreme drought problems, and provide only a very limited ion sorption capacity (Blume et al., 2016). However, a more detailed analysis reveals marked differences in the

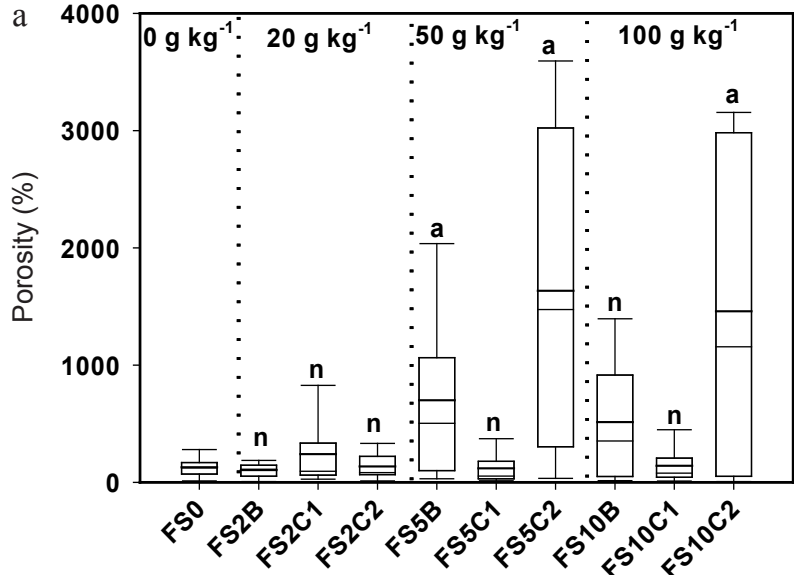

$\mathrm{b}$

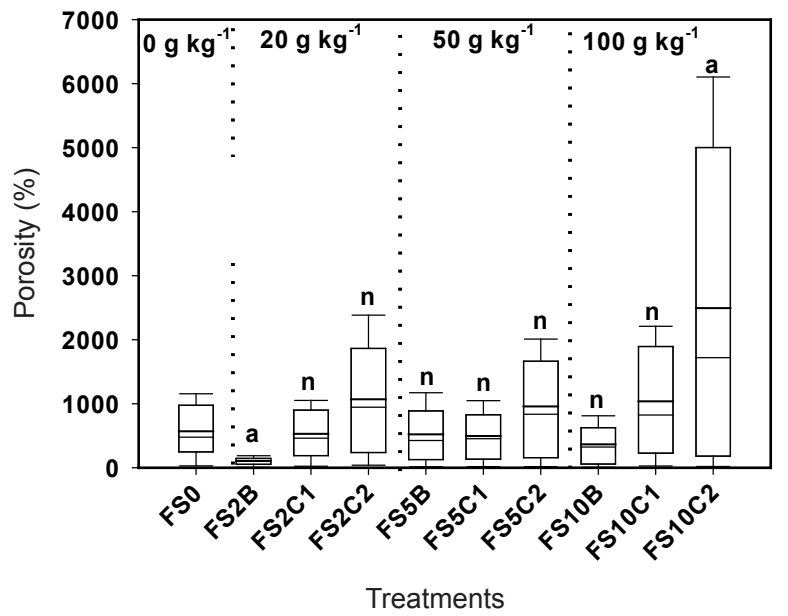

Fig. 2. Shear stress during the amplitude sweep test at: a) $0 \mathrm{kPa}$ and b) $-6 \mathrm{kPa}$ as influenced by type of amendment material and rate of amendment compared with the unamended fine sand; $\mathrm{a}-\mathrm{p}<0.05, \mathrm{~b}-\mathrm{p}<0.001$ and $\mathrm{n}-$ not significant when the effect of amendment is compared in one - ANOVA with the unamended fine sand; average of 10 samples per treatment.

effect of the different materials added. The Na-bentonite resulted in an expected increase of the water holding capacity, which apart from the saturation value, was always higher than the unamended material and it furthermore increased at more negative matric potential. In contrast, biochar or kaolinite required higher amounts to be added. These findings are in agreement with those of Obia et al. (2016) and Ward and Oades (1993) on biochar and clay amendment, respectively. Generally, the increased water retention in biochar and clay amended soils can usually be explained, in the first instance, as a consequence of the increase in internal surface area of the particles of the amended soils (Hartmann et al., 2009). The larger the internal surface area, the larger the liquid mass required to form one molecular layer of water (Ghezzehei and Or, 2001). Thus, the mechanism for increased water retention 


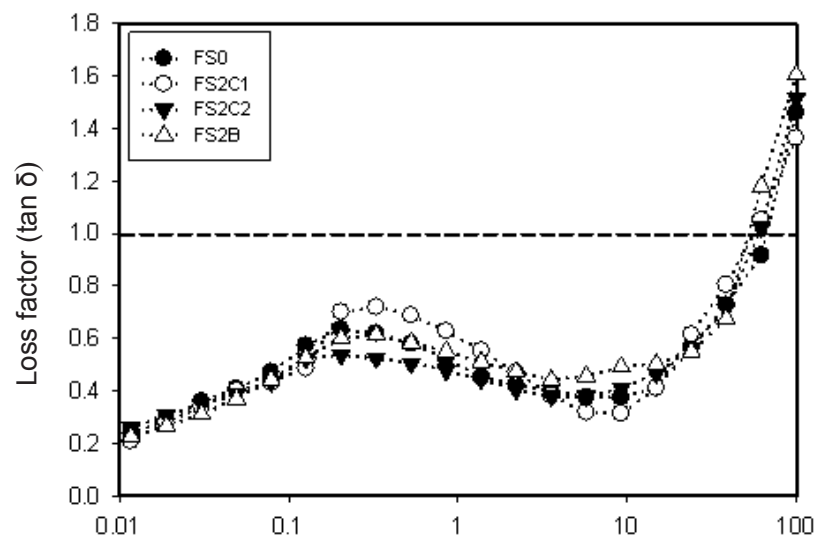

b
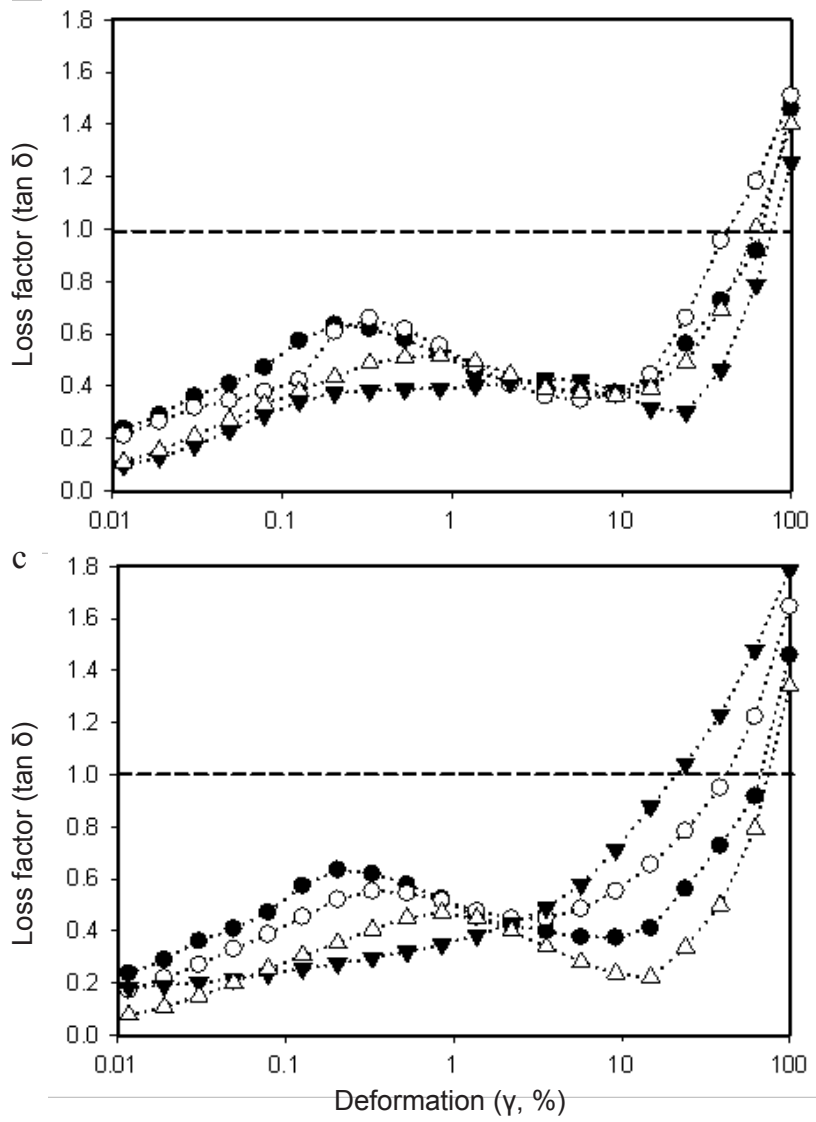

d
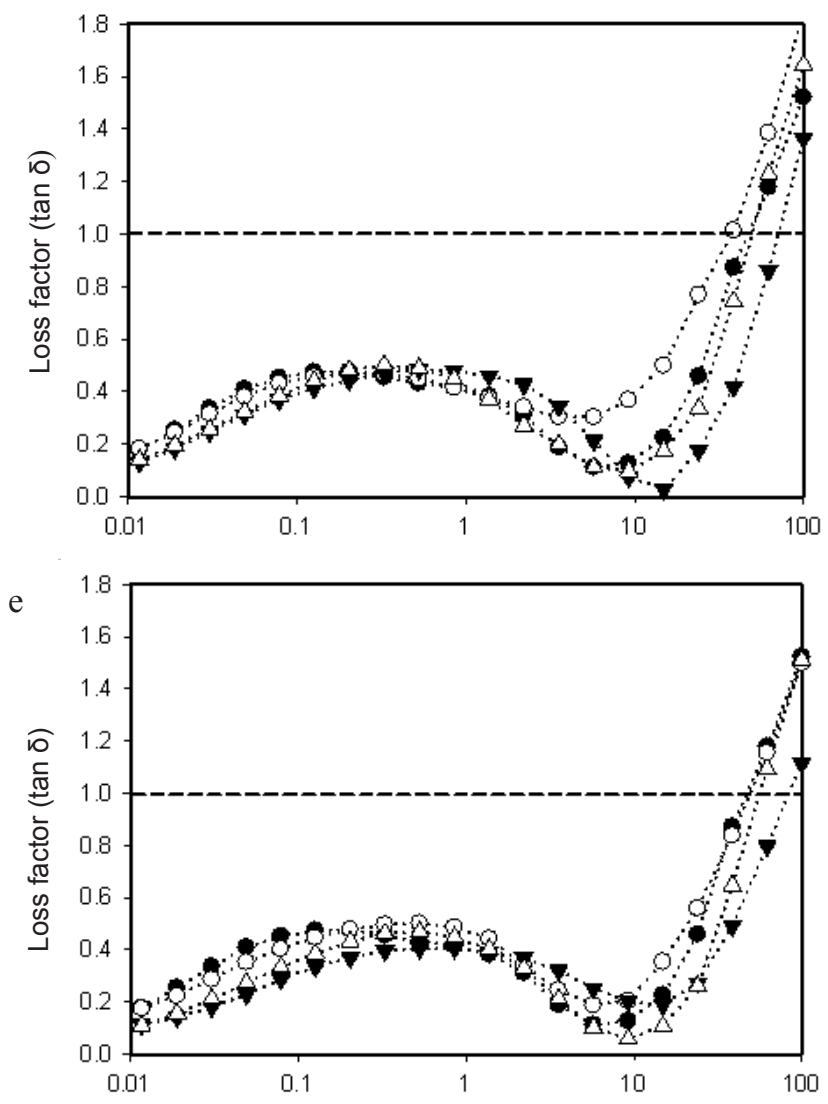

f

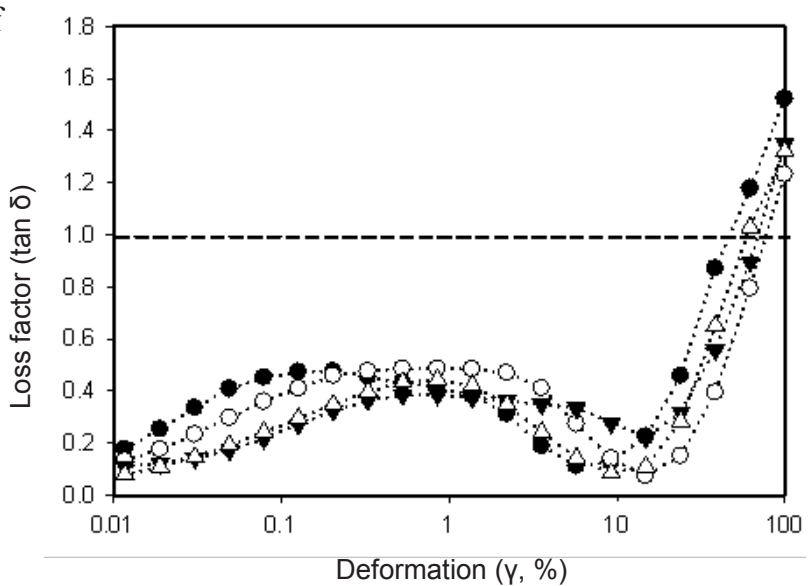

Fig. 3. Loss factor $\left(\tan \delta\right.$ ) of amended fine sand due to 20,50 and $100 \mathrm{~g} \mathrm{~kg}^{-1}$ rates of amendment with biochar (B), kaolinite (C1) or IS-80 (C2) at water saturation $0 \mathrm{kPa}(\mathrm{a}-\mathrm{c})$ and predrained condition $-6 \mathrm{kPa}(\mathrm{d}-\mathrm{f})$. The dashed line represents the transition from mainly elastic to mainly plastic behaviour and the point of intersection of the curve with the dashed line is the 'yield' point. Average of 10 samples per treatment.

by the amendment materials was observed to be well related to their particle sizes and behaviour when in contact with water (Fig. 1). Furthermore, the particle sizes of the added material also influence the hydraulic properties and functions of the amended soil, as can be noted from the changes in pore size distribution of the substrates. The relatively coarse grained biochar and kaolinite did not significantly decrease the wide coarse pores fraction (large macropore) until their amount (amendment rates) in the fine sand reached $\geq 50 \mathrm{~g} \mathrm{~kg}^{-1}$, while the fine clay (powdery) $\mathrm{Na}$-bentonite decreased both the wide and narrow coarse pore fraction, even at the lowest amendment rate. This was apparently due to the more complete in-filling of the large-sized pores of the fine-sand and the swelling of the particles when wetted (in contact with water), which changed the degree of saturation of the substrates (Hartge and Horn, 2014). 
T a b l e 2. Changes in integral $\mathrm{z}$ with types and rates of amendment material compared with the unamended fine sand at matric potential of $0,-6$, and $-15 \mathrm{kPa}$. Average of 10 samples per treatment

\begin{tabular}{ccccccccccc}
\hline $\mathrm{kPa}$ & $\mathrm{FS} 0$ & FS2B & FS5B & FS10B & FS2C1 & FS5C1 & FS10C1 & FS2C2 & FS5C2 & FS10C2 \\
\hline 0 & $19.5 \pm 3.6$ & $24.0 \pm 3.8$ & $26.2 \pm 3.2$ & $30.7 \pm 7.4$ & $24.1 \pm 1.5$ & $16.4 \pm 2.7$ & $12.1 \pm 0.7$ & $22.4 \pm 2.6$ & $37.4 \pm 4.5$ & $6.2 \pm 0.7$ \\
-6 & $26.4 \pm 5.2$ & $30.7 \pm 2.0$ & $33.0 \pm 2.4$ & $35.3 \pm 2.7$ & $12.8 \pm 2.5$ & $22.0 \pm 1.3$ & $43.3 \pm 4.3$ & $42.9 \pm 3.9$ & $39.3 \pm 3.1$ & $36.2 \pm 1.3$ \\
-15 & $14.6 \pm 3.9$ & $10.7 \pm 0.5$ & $20.4 \pm 2.28$ & $19.0 \pm 1.6$ & $14.8 \pm 1.3$ & $21.8 \pm 2.7$ & $39.7 \pm 1.1$ & $41.1 \pm 2.4$ & $37.2 \pm 3.8$ & $33.9 \pm 3.1$ \\
\hline
\end{tabular}

The mineralogy of the clay materials is also known to influence their water retention properties. The dominance of low activity clay mineral (kaolinite) is known to promote a face-to-face arrangement of the kaolinite plates, minimizing shrinkage and swelling (Miranda-Trevino and Coles, 2003). However, the possible presence of hydroxyl-interlayered vermiculite (HIV) as wedges between the kaolinite plates (Pai et al., 2004) may expand the available adsorption sites between the mineral layers, thereby enhancing water retention (Ajayi et al., 2013). This may explain why the effect of the kaolinite was very similar to that of biochar at the various rates of amendments. Smectite and montmorillonite that dominate the Na-bentonite material typically have unrestricted exchangeability of its intermediate layer cations and excellent swelling capacity in aqueous solutions (Markgraf et al., 2006). Thus, water retention is enhanced even at very negative matric potentials, where adsorptive forces dominate over capillary forces. Moreover, the internal surfaces of Na-bentonite are easily wettable, while the internal surfaces of kaolinite are practically non-wettable (Ghezzehei and Or, 2001). The interplay of these processes in water retention by Na-bentonite illustrated by Jacinto et al. (2012) therefore confirm our results and explain them. Water can either be stored in the soil macropores, having the physical and chemical properties of ordinary liquid water, or be attracted to the external surfaces of clay minerals, or held as interlayer water in the spaces between clay layers. The sorption of water into the interlayer space of smectites depends on the size and charge of the exchangeable cations, and on the value and localization of the layer charge (Laird, 2006), which increases with higher amendment rates. In spite of the enhanced moisture retention capacity of Na-bentonite, particularly under water stressed condition, it has been shown that the density of the water it holds, is increased (approximately by $2-5 \%$ ) over that of free water (Hawkins and Egelstaff, 1980; Fernandez and Jacinto et al., 2012; Rivas, 2005), and this may make it inaccessible to plants. We can therefore postulate and expect, that biochar and kaolinite amended fine-sand improve the rootability and plant growth conditions in contrast to the well described negative effect of pore-sealing with swelling clay (Stern et al., 1991).

The three amendment materials improved particle bonding in the fine sand in most instances, as detected in the curves of the loss factor $(\tan \delta)$, shear stress and inte- gral z. Generally, the data suggest that Na-bentonite would be more effective than biochar and kaolinite (in that order) in strengthening interparticle bond and improving the mechanical resilience of fine sand, if the rate of amendment is kept at $\leq 50 \mathrm{~g} \mathrm{~kg}^{-1}$. This is in agreement with the findings of Hartge and Horn (2014) who explained this strengthening effect with the various degrees of unevenness (texture) as well as the higher water saturation degree at less negative matric potential. With decreasing matric potential, the apparent cohesion between the particles increases but the depending on the rate of amendment, the grain size and shape and the dominant mineral material and the interparticle pore sizes. Considering the various parameters (shear stress and Integral z) at the matric potential $-6 \mathrm{kPa}$ (the potential at which most soil parameters are evaluated for agricultural application), the 3 rates of amendment with biochar and Na-bentonite increased the interparticle bonds. If, however, the kaolinite starts to dominate the mixture, its finer particles and higher water saturation at the given matric potential cause a slightly weakening of the bonds (Fredlund and Rahardjo, 1993; Hartge and Horn, 2016). The values of Integral $\mathrm{z}$ have been proven to be directly related to the elastic (resilience) or rigid (stiffness) behaviour of the interparticle particle bonds in several conditions (Holthusen et al., 2012; Markgraf et al., 2012). In the unamended condition, the fine sand particles are largely cohesionless and weakly structured (Abousnina et al., 2015), and can not withstand high shear stress values. The amend ments provided either clay or biochar coating on the finesand particles, which act synergistically to augment interparticle cementation depending on the chemical properties of the biochar and clay materials and the matric potential (Liu et al., 2015). Additionally, the amendment furthermore affects the cation exchange capacity (CEC) and reduces the water repellency risk (McKissock et al., 2000; Meisl et al., 2013). The process and nature of these coatings largely depict micromechanical behaviour (aggregation) in the amended fine sand. For the clay treatments, the aggregation is moderated by the dispersibility (flocculation / dispersion) behaviour and particle size of the clay minerals, whereas in the biochar treatment, it is determined by the level of sequestered organic carbon at the soil-biochar interphase (Ajayi et al., 2016; McKissock et al., 2000; Markgraf et al., 2012). The sodium saturated clay (Na-bentonite), when initially dispersed, tends to form 'strings' or aggregates, 
whereas the kaolinite crystals remained spread out covering the surfaces of the sand grains as the substrates dry out due to the difference in surface charge (McKissock et al., 2000). Finally, the mixture of the fine sand with the 3 amendments generally caused mostly better plant growth conditions, however, the amount needed to obtain such positive results require further economic evaluations and a site specific analysis of the complete altered soil hydraulic profiles.

\section{CONCLUSIONS}

1. The amendment of fine sand with biochar, kaolinite and Na-bentonite improved the water retention capacity and interparticle bonding of the substrate as a function of rate of amendment and matric potential.

2. Na-bentonite was more effective at increasing water holding capacity. Biochar was more effective at saturation due to the increased porosity, while kaolinite responds similarly to biochar. It is, however, shown that most of the water retained by the Na-betonite may not be available to plants, particularly at high amendment rate.

3. The materials improved particle bonding in the fine sand with the Na-bentonite proving to be more effective than biochar and kaolinite (in that order). The interparticle bonds are increased and enhance the resilience of fine sand, if the rate of amendment is kept at $\leq 50 \mathrm{~g} \mathrm{~kg}^{-1}$.

\section{ACKNOWLEDGEMENT}

The first author appreciates the Alexander von Humboldt Fellowship for the George Foster Research Fellowship.

Conflict of interest: Authors not declare conflict of interest.

\section{REFERENCES}

Abel S., Peters A., Trinks S., Schonsky H., Facklam M., and Wessolek, G., 2013. Impact of biochar and hydrochar addition on water retention and water repellency of sandy soil. Geoderma, 202-203, 183-191.

Abousnina R.M., Manalo A., Shiau J., and Lokuge W., 2015. Effects of light crude oil contamination on the physical and mechanical properties of fine sand. Soil Sediment Contam. An Int. J., 24, 833-845, doi:10.1080/1532038 3.2015.1058338

Ajayi A.E., Dias Jr, M.S., Curi N., and Oladipo I., 2013. Compressive response of some agricultural soils influenced by the mineralogy and moisture. Int. Agrophys., 239-246, doi:10.2478/v10247-012-0091-x

Ajayi A.E., Holthusen D., and Horn R., 2016. Changes in microstructural behaviour and hydraulic functions of biochar amended soils. Soil Till. Res., 155, 166-175, doi:10.1016/j.still.2015.08.007
Arthur E., Schjønning P., Moldrup P., Razzaghi F., Tuller M., and De Jonge L.W., 2014. Soil structure and microbial activity dynamics in 20-month field-incubated organic-amended soils. Eur. J. Soil Sci. 65, 218-230, doi:10.1111/ejss.12121

Bescansa P., Imaz M.J., Virto I., Enrique A., and Hoogmoed W.B., 2006. Soil water retention as affected by tillage and residue management in semiarid Spain. Soil Till. Res., 87(1), 19-27.

Blume H.-P., Brümmer G.W., Fleige H., Horn R., Kandeler E., Kögel-Knabner I., Kretzschmar R., Stahr K., and Wilke B.-M., 2016. Soil Science Springer, Springer, Berlin, Germany.

Bruun E.W., Petersen C.T., Hansen E., Holm J.K., and Hauggaard-Nielsen H., 2014. Biochar amendment to coarse sandy subsoil improves root growth and increases water retention. Soil Use and Management, 30, 109-118, doi: 10.1111/sum.12102

Cai W., Purich A., Cowan T., van Rensch P., and Weller E., 2014. Did climate change-induced rainfall trends contribute to the Australian Millennium drought? J. Clim., 27, 3145-3168, doi:10.1175/JCLI-D-13-00322.1

Dempster D.N., Jones D.L., and Murphy D.V., 2012. Clay and biochar amendments decreased inorganic but not dissolved organic nitrogen leaching in soil. Soil Res., 50(3), 216-221.

Donn S., Wheatley R.E., McKenzie B.M., Loades K.W., and Hallett P.D., 2014. Improved soil fertility from compost amendment increases root growth and reinforcement of surface soil on slopes. Ecol. Eng., 71, 458-465, doi:http://dx.doi.org/10.1016/j.ecoleng.2014.07.066

Farrell C., Ang X.Q., and Rayner J.P., 2013. Water-retention additives increase plant available water in green roof substrates. Ecological Eng., 52, 112-118, http://doi.org/http://dx.doi.org/10.1016/j.ecoleng. 2012.12.098

Fernandez A.M. and Rivas P., 2005. Analysis and distribution of waters in the compacted FEBEX bentonite: pore water chemistry and adsorbed water properties. In: Advances in Understanding Engineered Clay Barriers (Eds E.E. Alonso, A. Ledesma), Leiden, Netherlands.

Fredlund D.G. and Rahardjo H., 1993. Soil mechanics for unsaturated soils. Wiley and Sons Inc., Stuttgart, Germany.

Ghezzehei T.A. and Or D., 2001. Rheological properties of wet soils and clays under steady and oscillatory stresses. Soil Sc. Soc. America J., 65(3), 624-637.

Hartge K.H. and Horn R., 2016. Essential Soil Physics. An introduction to soil processes, functions, structure and mechanics (Eds R. Horton, R. Horn, J. Bachmann, S. Peth). Schweizerbart Sci. Press, Stuttgart, Germany.

Hartmann P., Fleige H., and Horn R., 2009. Physical properties of forest soils along a fly-ash deposition gradient in Northeast Germany. Geoderma, 150, 188-195.

Hawkins R.K. and Egelstaff P.A., 1980. Interfacial water structure in montmorillonite from neutron diffraction experiments. Clays Clay Miner., 28(1), 19-28. 
Holthusen D., Jänicke M., Peth S., and Horn R., 2012. Physical properties of a Luvisol for different longterm fertilization treatments: I. Mesoscale capacity and intensity parameters. J. Plant Nutr. Soil Sci., 175, 4-13, doi: 10.1002/jpln.201100075

Jacinto A.C., Villar M.V., and Ledesma A., 2012. Influence of water density on the water-retention curve of expansive clays. Géotechnique, 62, 657-667, doi:10.1680/ geot.7.00127

Johnson M.S., 1984. The effects of gel-forming polyacrylamides on moisture storage in sandy soils. J. Sci. Food Agric., 35, 1196-1200.

Karbout N., Moussa M., Gasmi I., and Bousnina H., 2015. Effect of clay amendment on physical and chemical characteristics of sandy soil in arid areas: the case of ground south - eastern Tunisian. Appl. Sci. Reports, 11, doi:10.15192/PSCP.ASR.2015.11.2.4348

Laird D.A., 2006. Influence of layer charge on swelling of smectites. Appl. Clay Sci., 34(1-4), 74-87.

Liang C., Zhu X., Fu S., Méndez A., Gascó G., Paz-Ferreiro J., 2014. Biochar alters the resistance and resilience to drought in a tropical soil. Environ. Res. Lett. 9, 64013.

Liu Z., Liu F., Ma F., Wang M., Bai X., Zheng Y., Yin H., and Zhang G., 2015. Collapsibility, composition, and microstructure of a loess in China. Can. Geotech. J., doi:10.1139/cgj-2015-0285

Markgraf W. and Horn R., 2006. Rheological-stiffness analysis of $\mathrm{K}+$-treated and $\mathrm{CaCO}_{3}$-rich soils. J. Plant Nutr. Soil Sci., 169, 411-419, doi:10.1002/jpln.200521934

Markgraf W., Peth S., and Horn R., 2006. An approach to rheometry in soil mechanics: structural changes in bentonite, clayey and silty soils. Soil Till. Res., 91, 1-14.

Markgraf W., Watts C.W., Whalley W.R., Hrkac T., and Horn R., 2012. Influence of organic matter on rheological properties of soil. Applied Clay Sci., 64, 25-33.

McKissock I., Walker E.L., Gilkes R.J., and Carter D.J., 2000. The influence of clay type on reduction of water repellency by applied clays: A review of some West Australian work. J. Hydrol., 231-232, 323-332, doi:10.1016/S0022-1694(00)00204-3

Meisl T., Dubský M., Šrámek F., and Nečas T., 2013. The effect of clay amendment on substrate properties and growth of woody plants. Acta Universitatis Agriculturae et Silviculturae Mendelianae Brunensis, 60(8), 163-170.
Miranda-Trevino J.C. and Coles C.A., 2003. Kaolinite properties, structure and influence of metal retention on $\mathrm{pH}$. Appl. Clay Sci., 23, 133-139.

Mulcahy D.N., Mulcahy D.L., and Dietz D., 2013. Biochar soil amendment increases tomato seedling resistance to drought in sandy soils. J. Arid Environ., 88, 222-225.

Obia A., Mulder J., Martinsen V., Cornelissen G., and Børresen T., 2016. In situ effects of biochar on aggregation, water retention and porosity in light-textured tropical soils. Soil Till. Res., 155, 35-44, doi 10.1016/j. still.2015.08.002

Pai C.W., Wang M.K., King H.B., Chiu C.Y., and Hwong J.-L., 2004. Hydroxy-interlayered minerals of forest soils in A-Li Mountain, Taiwan. Geoderma, 123, 245-255.

Roper M.M., Ward P.R., Keulen A.F., and Hill J.R., 2013. Under no-tillage and stubble retention, soil water content and crop growth are poorly related to soil water repellency. Soil Till. Res., 126, 143-150.

Sanoway Australia, 2006. SANOPLANT. Vol. 2010, Australia. Available at: http://www.sanoway.com.au/sanoplant. overview.ews (accessed 2.11.150)

Schramm G., 1994. A practical approach to rheology and rheometry. Karlsruhe: Haake, Germany.

Shahid S.A., Qidwai A.A., Anwar F., Ullah I., and Rashid U., 2012. Improvement in the water retention characteristics of sandy loam soil using a newly synthesized Poly(acrylamide-co-acrylic Acid) $/ \mathrm{AlZnFe}_{2} \mathrm{O}_{4}$ superabsorbent hydrogel nanocomposite material. Molecules, 17, 9397-9412.

Stern R., Ben-Hur M., and Shainberg I., 1991. Clay mineralogy effect on rain infiltration, seal formation and soil losses. Soil Science, 152(6), 455-462.

Vyalov S.S., 2013. Rheological fundamentals of soil mechanics. Developments in Geotechnical Engineering 36, Elsevier, Amsterdam, Netherland.

Ward P.R. and Oades J.M., 1993. Effect of clay mineralogy and exchangeable cations on water repellency in clay-amended sandy soils. Soil Research, 31(3), 351-364.

Yoo G., Kim H., Chen J., and Kim Y., 2014. Effects of biochar addition on nitrogen leaching and soil structure following fertilizer application to rice paddy soil. Soil Sci. Soc. Am. J., 78, 852-860, doi:10.2136/sssaj2013.05.0160 